\title{
LOS HOMBRES DE CLARA LAIR: \\ RETRATOS MASCULINOS EN UN AMOR EN NUEVA YORK Y ARRAS DE CRISTAL
}

\author{
POR \\ JORGE ROSARIO \\ Long Island University
}

[...] vuelve de nuevo a amar. camina girándose hacia atrás

y recupera

la sangre en todo el cuerpo de un solo latigazo de sus venas. retoña a toda la gloria en un instante: regresa al mundo del lado de su amante. mas he aqui que, temeroso infundido, es el amado quien se torna fugitivo. [...] llora Dafne abandonada en la ribera,

llora, llora tras él, votaliza su cuerpo en lágrimas que corren [...]

Ferré, Fábula 43

La obra poética de Clara Lair(1895-1973) se distingue por su inquisitivo y elocuente cuestionamiento de la conducta observable y psiquis operativa del hombre. Con su perspicaz y agudo escrutinio, la poeta puertorriqueña polemiza los bríos y las prácticas que retratan al hombre desde la configuración patriarcal de su época en los poemarios Un amor en Nueva York (1920-1928), Arras de cristal (1937), Trópico amargo y Más allá del poniente (1950). ${ }^{1}$ Como mujer interpelada por paradigmas que magnifican al hombre, la voz poética de Lair manifiesta registros convencionales de géneros cuando se relaciona con los hombres en calidad de amada. Sin embargo, el devastador atropello de sus sentimientos y cuerpo revierte su inmersión dentro de tal configuración para develar cómo son y qué quieren los hombres de la mujer. ${ }^{2}$

1 Se citan los poemas directamente de De la herida a la gloria: La poesía completa de Clara Lair (2003) editada por Mercedes López Baralt. Véase también la primera edición de las obras completas de Lair publicadas por Vicente Géigel Polanco (1979).

2 La poesía de Clara Lair ha pasado casi inadvertida si se compara con la obra de sus coetáneas posmodernistas Delmira Agustini, Gabriela Mistral, Alfonsina Storni, Juana de Ibarbourou y Julia de Burgos de principio de siglo xx. Estas poetas declaran sus propias identidades pero a su vez dialogan 
Aunque la poesía y las conjeturas de los supuestos amantes de Clara Lair emergen sincrónicamente, la especulación popular rebasa la atención crítica dada a la obra literaria de la poeta. ${ }^{3}$ Este ensayo se distancia de la especulación popular y a cambio estudia e retrato de los "hombres" y la representación masculina según la configuración patriarcal de la primigenia "identidad" de la voz poética en Un amor en Nueva York y en Arras de cristal. En el proceso de "narrar" la búsqueda del príncipe azul, la voz poética presenta una galería de hombres cuyos retratos sicológicos se distancian del candor del "amor" y de las "arras" cuando interactúan con la amada. ${ }^{4}$ Partiendo de esta premisa también se estudia cómo la voz poética revela un vívido deseo de fusión con el hombre mientras zigzaguea entre ser la mujer "cuasi" tradicional y la transgresora de convencionalismos cuando cata los sabores y nuevos saberes que provocan su deseo de fusión. Este proceso de aprendizaje permite que Lair polemice la configuración patriarcal que culturalmente otorga autoridad, prestigio social y trascendencia al hombre mientras denuncia serias carencias, jactancias del ego y disfunciones masculinas. El ensayo igualmente analiza la implícita voz femenina que devela su identidad y psiquis operativa en la medida que explora e interactúa con los hombres hasta el momento de su rebelión en que analiza su experiencia para entonces eclosionar su identidad de mujer nueva. La enunciación de cómo la voz poética se relaciona, sueña y socava a los hombres resulta en la más elocuente confirmación de su reconstruida identidad femenina.

"Ama sólo en silencio su dama, la Fortuna"

Un amor en Nueva York emerge de la experiencia de Lair en Nueva York a raíz de la salida de su familia de Puerto Rico en 1918. Como le ocurriera a Gómez de Avellaneda, ${ }^{5}$ las prácticas imperantes del patriarcado y del concepto familia provocan que la joven soltera emigre con su familia al nuevo destino. Mientras la Avellaneda emigra a la estremecida España del siglo XIX, Lair enfrenta una convulsa metrópoli en

entre sí para refractar la indolencia patriarcal y el abatimiento amoroso. Aunque han sido tildadas de neorrománticas, el discurso político de las poetas polemiza el peso ancestral patriarcal, la asimetría de los géneros y la configuración amatoria opresora. El locuaz erotismo, la celebración de la maternidad y búsqueda de la reivindicación de sus capacidades, sexualidad, género y poder político.

Véase "Entre Clara y Julia" de Rosario Ferré, donde se señala la indiferencia crítica a la poesía de Clara Lair y Julia de Burgos. Tiempo después de este artículo publicado en 1986, la obra de Lair ha recibido mayor difusión gracias al documental Una pasión llamada Clara Lair de Ivonne Belén y a la contribución de Mercedes López Baralt, pero los estudios de su obra resultan todavía escasos.

Aunque se podría analizar cada poema y poemario individualmente, Clara Lair escribe con visión y unidad, lo que permite la lectura de los poemarios como si se tratara de una historia.

Para mayor información sobre el destierro de la Avellaneda y su poesía a raíz de esta experiencia, véase mi ensayo "Registros de la patria y la nostalgia en Gertrudis Gómez de Avellaneda y Lola Rodríguez de

17. Revista Iberoamericana, Vol. LXXIX, Núms. 244-245, Julio-Diciembre 2013, 703-723 ISSN 0034-9631 (Impreso) ISSN 2154-4794 (Electrónico)
Nueva York, donde reside hasta 1932 cuando regresa a su patria. La nostalgia de la patria y el choque cultural provocan que Lair escriba uno de los primeros poemarios en literatura hispana que polemiza la convivencia como extranjera en la ciudad de los rascacielos. Lair y Un amor en Nueva York dialogan con José Martí en Versos libres (1882) y con Juan Ramón Jiménez en Diario de poeta recién casado (1916-1917), poetas que transforman su experiencia de vivir en Nueva York previo a Federico García Lorca en Poeta en Nueva York (1940). ${ }^{6}$ El poemario de Lair también centraliza en el retrato masculino individual y colectivo llamando a los hombres "Príncipe de Park Avenue" (9), "yankee de gala aristocracia" (9), "grupo de hombres, secos, apresurados" (3). Así, la voz poética controvierte la íntima asociación del hombre con la obsesiva acumulación del dinero en la década de 1920, debate que se mantiene vigente por las disfunciones masculinas señaladas. Tras observar cómo el hombre se convierte en representación del capitalismo, Lair se transforma en una aguda retratista que devela fijaciones y compulsiones; y polemiza cómo la vida del hombre de negocios gira en torno a su relación con el dinero. Contrario a la indulgente sociedad que reconoce las ignominias pero aún así admira al hombre acaudalado, la voz poética lo retrata como sujeto patológico desde la posición subalterna de la "quieta taquígrafa [...] de un raro perfil" (10) "que le calla un amor" (9). ${ }^{7}$

Robert E. Gould en "Men, Money and Masculinity" destaca que el dinero subsana y oblitera la devaluación sicológica y física del hombre que está insatisfecho/decepcionado con la representación de su propia masculinidad. Con la acumulación y el despliegue de bienes no sólo el hombre se siente poderoso, libre y su autoestima se engrosa, sino que la sociedad lo acepta porque "In our culture money equals success" (61). Así el hombre se confirma como sujeto poderoso y disfraza su necesidad sicológica y dilema de autoestima con la agresiva agenda de trabajo, con el éxito visiblemente logrado y con la acumulación de bienes (61-67). La voz poética de Un amor en Nueva York carece de la información para precisar el origen de la compulsión por la riqueza, pero su minuciosa observación presenta el drama de "El Príncipe de Park Avenue" en su impetuoso afán por lograr el estatus que su propia psiquis no le confirma:

Cuando no hay sino la pared amarilla

Y el tín-tín-retintín de la maquinilla,

Llega indiferente Don Felipe de Rior.

Don Felipe es un yankee de gala aristocracia, $[\ldots]$

Véase El poeta y la ciudad de Dionisio Cañas, donde se traza y analiza el tema destacado en la literatura hispana. Específicamente Cañas interpreta la obra de Martí, Jiménez, Lorca y del poeta puertorriqueño Manuel Ramos Otero.

Mercedes López Baralt cita una carta de Lair envíada a su amigo Félix Tió donde la poeta subvierte ese poder masculino: "Yo trabajé en esa firma [...] los primeros años de 1920. [...] Eran gentes pesadas, hombres viejos que trataban de sustituir la pérdida de su virilidad con rudos gestos de amor (xi)".

Revista Iberoamericana, Vol. LXXIX, Núms. 244-245, Julio-Diciembre 2013, 703-723 ISSN 0034-9631 (Impreso) $\quad$ ISSN 2154-4794 (Electrónico) 
Eternamente en víspera o término de un viaje,

Don Felipe de Rior es aquel personaje

Que siempre va de prisa y no lleva un reló.

Un título moderno: Príncipe de Park Avenue.

Su trono: una oficina... Y su gran homenaje,

el vaivén de papeles de una corporación.

[...] Don Felipe, más seco y opaco que el hastío, ama sólo en silencio su dama, la Fortuna.

[...] ¡Don Felipe... qué acierto al que no puedo amar! (9-10)

La indiferencia, la prisa, su mentalidad "yankee" imperialista, su trono y gran homenaje crean el abismo entre el aristócrata Príncipe de Park Avenue, y la invisible " [...] taquígrafa...que le calla un amor" (9). Esta no es la noble aristocracia de la princesa de Rubén Darío, tal como se intuye por la musicalidad del poema, sino la aristocracia lograda a través del recaudamiento de bienes. Así se desenmascara al Príncipe y se presenta como retrato burgués e impío del hombre acaudalado en Nueva York. El "Príncipe" es un maestro en la economía de los sentimientos: "llega indiferente", "va de prisa", "más seco y opaco que el hastío", "es callado, y seco, y altanero" (9), sin embargo "ama sólo en silencio su dama, la Fortuna" la que resulta idónea y sicológicamente placenter para no experimentar otros sentimientos que lo desvirtúen de su trono (10). Con su cuerpo, él establece la distancia entre el jefe, los subordinados y la invisible taquígrafa que rastrea sus movimientos. Gould también afirma que: "If the drive to accumulate money is to neutralize the anxiety stemming from an unstable self-image, then there can never be enough" (66). Por tanto, si para el Príncipe, "su gran homenaje [es],/e vaivén de papeles de una corporación", el caudal acumulado engrosa su autoestima y así perenniza su lucha para desdibujar la devaluación que sufre como hombre (9). Pero, este cíclico déficit de su interior es su hermético y aparente secreto. Su cuerpo "callado, seco y altanero" revela contrariedades, mas el dinero multiplicado solapa sus patologías. Así este hombre convierte su desmedida fijación en un acto histriónico para satisfacción propia e impresionar a quienes lo admiran y son indulgentes con él ya que la agresiva adquisición de bienes lo transforma en lo deseado en el espacio público. En el acto histriónico, el "Príncipe" crea al doble poderoso, masculino y libre de sus privadas turbaciones. El título de "príncipe" confirma la creación de su estatus social, económico y sicológico, y su dispositivo para lograrlo ha sido el dinero y la enfermiza fijación para retratar una fantasía del doble poderoso y de gran estatus social.

El poema "Al presidir el H...Trust Company" magnifica quién es este hombre y cómo su única existencia se vincula a instituciones y empresas íntimamente ligadas a capitalismo. Tras concienciarse, la voz poética concluye que el "Príncipe" es un sujeto unidimensional que le despierta pasiones; mas como sólo la fortuna lo regocija, ella da rienda suelta a la naturaleza de tal sujeto en vez de aspirar a una relación.

Revista Iberoamericana, Vol. LXXIX, Núms. 244-245, Julio-Diciembre 2013, 703-723 ISSN 0034-9631 (Impreso) ISSN 2154-4794 (Electrónico)
Que tengas suerte, Príncipe de los ojos radiosos...

Que tu Banco se llene de ritmos fabulosos...

Que tu prestigio ensalce diamantes y zafiros...

(No versos y suspiros).

Que The Wall Street Journal te dedique un sincero

poema financiero,

donde tu nombre rime con el nombre de Ford..

(No con "dolor y amor")

Que balances y cuentas te digan la canción

que se calló mi corazón..

Que tengas suerte, Príncipe de la fría gentileza.

Pero que nunca el oro eclipse tu belleza,

y si alguna te quiere... que te quiera por ti;

y te quiera por mí. (13)

El banco lleno de ritmos fabulosos y el poema financiero en "The Wall Street Journal" magnifican la caricatura burguesa del "Príncipe", quien grotescamente goza de su poderoso estatus. La carencia de caudal del "Príncipe" no sólo sería su miseria económica sino también anímica ya que el capitalismo es el único registro de existencia ante la sociedad y ante sí mismo. El no sabría quién es sin su trabajo, sin la opulencia y sin el reconocimiento que devienen de sus prácticas. El apóstrofe y el repetido subjuntivo-que tengas suerte, que tu Banco se llene, que tu prestigio se ensalce-convierten al poema en una postal de despedida o en la renuncia de la taquígrafa, donde sarcásticamente le desea bienestar con la única nomenclatura -balances, banco, cuentas- que este sujeto comprende. Con una efervescente enunciación, la voz poética se desintoxica y más allá de liberarlo a él se libera ella misma de la enfermiza conexión de los dispositivos que le otorgan placer e identidad al "Príncipe" ya que sus valores son incompatibles.

Aunque el "Poema VI" dialoga con los anteriores, éste clarifica que el sujeto capitalista sí recurre a sus emociones pero no las canaliza precisamente de forma positiva ya que está sujeto a la forma de vida operativa de su mundo y a la meta diaria de productividad y superávit:

¡Qué vale mi canción! ¡Qué lo que eres,

ni lo que soy, ni el otro que te ofrezco

cuando llena el santuario oficinesco

una ilusión tenaz por Rockefeller!

He aquí mi oro: el inaudito giro del corazón; las mieles escondidas..

Las palabras candentes y sentidas;

¡el beso eterno que creó un suspiro!
Revista Iberoamericana, Vol. LXXIX, Núms. 244-245, Julio-Diciembre 2013, 703-723 ISSN 0034-9631 (Impreso) 
[...] mientras tú en las mañanas de más fríos

vas a decirle tu canción de hastíos

al cajero más rudo de tu Banco. (8)

Como "la ilusión tenaz por Rockefeller" resulta la meta del sujeto capitalista, él no valora "el inaudito giro del corazón; las mieles escondidas... las palabras candentes y sentidas" de la taquígrafa. Mientras ella emerge en espera de atención o reciprocidad afectiva, él enuncia "su canción de hastíos al cajero más rudo" (8). La economía de los sentimientos del sujeto capitalista clausura posibilidades afectivas y amorosas porque sólo ve empleados genéricos que cumplen funciones y contribuyen a su superávit. S su meta no se logra según dispone, su repugnancia emerge porque vive exclusivamente para incrementar su capital. La voz precisa que cuando las emociones se fulguran, los afectos ni las posibilidades de ser persona se manifiestan ya que eso se erradica de la vida diaria. También destaca que el empresario capitalista mantiene vigente una imagen de agresiva autoridad como estrategia para incrementar su caudal y para controlar a los otros. El capitalismo retrata al hombre como dramático fanfarrón y máquina reproductora.

Nigel Edley y Margaret Wetherell afirman en Men in Perspective que: "the socia conflicts of capitalism become embodied in the nervous systems and energies of men, producing distinctive and entirely habitual sets of gestures, even tones of voices and personalities" (99). El "Poema I" retrata cómo el capitalismo genera un estilo de vida que interpela y estimula las necesidades del hombre en su desmedido afán por e dinero. Como el capitalismo provee su nueva identidad, ni la colectividad masculina ni el hombre individual se percatan de cuán despersonalizado y deshumanizante son las prácticas de su encarnación.

Era un grupo de hombres secos apresurados, -con un cigarro mustio tronchado entre los dientesque hablaban de petróleo, de acciones y de agentes en un salón abierto, de libros envidriados.

Y era un salón conjunto, oscuro, emparedado, de viejas maquinillas, papeles y cajones, y era un pasillo corto entre los dos salones, un único pasillo... de rejas circundado..

Sin gestos, sin miradas, sin voz y sin sonrisa cruzaban el pasillo los hombres de la prisa.. y era a su paso, el oscuro salón más ceniza... (3)

Esta clonación de sujetos, cuyos cuerpos y mentalidad resaltan la dinámica del hombre de negocios, se inscribe en una agenda común y unísona. Así la individualidad

Revista Iberoamericana, Vol. LXXIX, Núms. 244-245, Julio-Diciembre 2013, 703-723 ISSN 0034-9631 (Impreso) ISSN 2154-4794 (Electrónico) del sujeto desaparece y se funda una fraternidad de capitalistas regida por paradigmas y transacciones orquestadas. La fraternidad demanda que el hombre valide su prestigio social a través del dinero, de la elocuencia e inteligencia y mediante el porte del mustio cigarro. Unos a otros se legitiman, compiten y responden al ideario masculino cultural que ellos mismos crean dentro del espacio público y grupo de poder. Como se evidencia, el cuerpo y los sentimientos del sujeto masculino se tornan en carencia porque el capitalismo cancela gestos, miradas, voces, sonrisas; y a cambio se deviene la economía de los sentimientos que despersonaliza. Ahora la coreografía unísona de "los hombres de la prisa" impele mayor productividad en el menor tiempo posible y emerge la pérdida de la individualidad y la deshumanización cuando el cuerpo masculino "sin gestos, sin mirada, sin voz y sin sonrisa" se convierte en máquina programada y cíclica. El próximo día de operaciones se replica el mismo retrato en movimiento: los hombres secos y apresurados vuelven al salón con el mustio cigarro y conversan de lo mismo ya que el capitalismo establece patrones y prácticas de existencia entre los fraternos inmersos. La despersonalización erradica los gestos particulares y las emociones que le otorgan a cada individuo su irrepetible personalidad para transfigurarlo en un sujeto genérico hecho a modo y semejanza del capitalismo.

Edward Hallowell y William Grace en "Money Styles" dividen en cuatro categorías mayores los tipos de sujetos en relación a sus prácticas con el dinero: the enthusiasts, the spenders, the underinvolved, the skeptics (16-26). Según su teoría se podría clasificar a los hombres de Lair como sujetos entusiastas, los que ven al dinero como dispositivo de poder, autoestima y emancipación. Como destacan Hallowell, Grace y presenta Clara Lair, este sujeto es el menos ambivalente en su relación con el dinero. También es el más agresivo y el que menos se siente culpable o intimidado al poseer o aspirar a más. Como el sujeto entusiasta, el hombre capitalista retratado por Lair "gets up for the game, each day starting with a psyche session where he whips himself into the proper frame of mind for the day's game" (Hallowell 17). Desde esta plataforma el capitalismo no permite que el "Príncipe" como representación de todos se reconozca como víctima de sus propias prácticas porque así traza sus metas en la mañana y se regocija de su triunfo o exaspera su frustración al final del día. El está inmerso dentro de una mecanización que desvirtúa sus posibilidades humanas, transforma su cuerpo, reconfigura sus emociones y participa de un ciclo competitivo que sólo la muerte detiene. Por tanto, Lair anticipa su soledad porque el hombre de un "rápido saludo lisonjero" (9) restringe su intimidad y exilia sus afectos. El sujeto entusiasta como el "Príncipe" no sólo engrosa su autoestima cuando oblitera su devaluación íntima, sino que robustece la esencia del capitalismo al producir el superávit para el sistema, el cual desdibuja sus necesidades sicológicas. Ronald F. Levant afirma que: "The requirements are more severe in societies where life is harsher. [...] The test for manhood are never finished; it is hard to find a permanent place among the community of men" (392). La enumeración de signos de poder y de estatus tales como Park Avenue, yankee de gala aristocracia, Rockefeller, Trust

Revista Iberoamericana, Vol. LXXIX, Núms. 244-245, Julio-Diciembre 2013, 703-723 ISSN 0034-9631 (Impreso) ISSN 2154-4794 (Electrónico) 
Company, Wall Street Journal y Ford testimonian la jerarquía lograda dentro y ante los de su mundo. Por ende resulta imperativo mantener su ritmo productivo para confirmar los bienes materiales que posee, para disfrutar del estatus de poder y así revertir lo que carece con su superávit sicológico. En palabras de Lair, él: "ama sólo en silencio su dama, la Fortuna..." ya que sólo él conoce la elocuencia de su hermético secreto y hasta donde tiene que esforzarse para que la sociedad indulgente no vea su precariedad sino su magnanimidad y opulencia(10). Aunque el título del poemario sugiere la ilusión amorosa de una joven taquígrafa en Un amor en Nueva York, el amor del "Príncipe" al dinero y las implicaciones de esta pasión resultan la única experiencia registrada.

"Habrias de llegar, tú mi Romeo"

Lamentablemente la poesía de Lair, la que sintoniza con las preocupaciones de Delmira Agustini, Alfonsina Storni, Juana de Ibarbourou y Julia de Burgos, sólo ha recibido escasa atención crítica como ya había señalado. No obstante, Lair evidencia la perspicacia ideológica y la contundencia poética que la separa de las escritoras de su generación. En Arras de cristal se agudiza el retrato masculino tan propio de $U n$ amor en Nueva York pero ahora con mayor agresividad física y apertura emocional cuando la mujer se relaciona con los hombres en la aparente búsqueda de las arras, de una relación formal con el hombre. Aquel sujeto capitalista unidimensional que se flagelaba matinalmente se transforma ahora en debacle erótica-amorosa ya que a la voz poética se le dificulta procesar el hedonismo, la concupiscencia masculina y sus propios deseos de fusión dentro de la configuración patriarcal. Por tanto, los encuentros muestran la complejidad de la poética amatoria dentro de esta estructura para ofrecerle a ella la experiencia de aprendizaje, el nuevo proyecto de vida y la explicación de por qué las arras son de cristal.

Los poemas "Pardo Adonis (In Memoriam)" y "Lullaby mayor" homenajean al hombre como esclavo erótico vital ya que la ausencia de éste genera los pesares de la amada. Aunque la voz poética se proyecta como mujer libre que celebra su sexualidad, su celebración no le gratifica su presente. "Pardo Adonis" se monta dentro de las múltiples versiones de la mitología mediterránea que elevan a Adonis a gran amo y señor, que lo eternizan por su deslumbradora virilidad y belleza, que relatan su temprana muerte por los celos desatados de Ares y de su amante Afrodita. ${ }^{8}$ En la versión caribeña de "Pardo Adonis (In Memoriam)" la voz enuncia:

De la uva exhausta de mis cinco sentidos exprimo en tu honor, pardo Adonis, esta gota de vino.. ¿Vino de tedio tinto!

\footnotetext{
8 Véase Greek Religion de Walter Burkert y The Gardens of Adonis de Marcel Detienne.
} ISSN 0034-9631 (Impreso) ISSN 2154-4794 (Electrónico)
¡Hincha a solas el río seco de mi instinto!

¡Hincha y suelta mi río hacia el bosque perdido de lo desconocido!

El día, pardo Adonis, donde mi tedio estanco,

es todo blanco... [...]

¡Mis ojos quieren sombra!

¡Mis ojos quieren triste resplandor!

Mi pena quiere alfombra

y cortinaje negro... (29)

Lair refunde el mito recreando a una Afrodita esclavista que desea el reencuentro sexual de "éxtasis hondo/ de selva de caoba, de canela, de miel" con su esclavo Adonis para transformar su abulia de mujer blanca (29). Con gran frenesí, la Afrodita esclavista afirma que su libido está exaltado y que los recuerdos del olor, textura y sabor del pardo Adonis -encarnados en la caoba, la canela y la miel-exacerban su deseo. La configuración semítica de Adonis - Adonai- como señor y amo se cumple a medias porque la mujer es quien encarna el amo blanco y con tono imperativo le demanda a Adonis: "ihincha a solas el río seco de mi instinto!/ ¡hincha y suelta mi río hacia el bosque perdido/ de lo desconocido!" (29). Pero ahora ella es la esclava de su pasión ya que conecta su deseo del presente al ardiente pasado, cuando gozaba de la deidad parda.

[...] Mi pena quiere frente a sí el allegro

de máscara de tu reír sin fondo.

¡Tú risa, flor de hiel!

De mi guarda, la raza, fugitiva me escondo,

y un éxtasis mi alma a tu cuerpo le roba...

éxtasis hondo

de selva de caoba, de canela, de miel. (29)

Benítez Rojo señala en La isla que se repite que "cada raza y cada híbrido [...] bajo la bandera de su piel, porta [...] una historia local, una sociología y una economía que si bien diferentes y anacrónicas entre sí, presentan una turbulencia común" (218). Ciertamente, el cuerpo pardo porta la historia oficial del atropello sufrido por los esclavos en las plantaciones caribeñas. El estado de suspensión del ama blanca relata la historia no oficial develando que las 'plantaciones' no se limitaban a la cosecha y que las relaciones de poder entre amo y esclavo no siempre seguían el patrón de Cecilia Valdés de Cirilo Villaverde, donde la mujer esclava es el objeto del deseo y el amo blanco el hostigador sexual. María D. Pieropan afirma que: "Lair alaba lo negro como lo auténtico afirmando que su amante negro la ha salvado del tedio de su propia raza blanca" (673). No obstante, salvar del propio tedio a la raza blanca es categorizar a Adonis sólo como objeto erótico poseído. Como esclavo o señor opresor, la voz poética

Revista Iberoamericana, Vol. LXXIX, Núms. 244-245, Julio-Diciembre 2013, 703-723 ISSN 0034-9631 (Impreso) ISSN 2154-4794 (Electrónico) 
no permite superar el estatus 'pardo' de Adonis por la historia de su piel. Él encarna el gozo de la otredad, la opresión y la conquista de lo exótico. La duplicidad de Adonis como esclavo y fetiche ciertamente celebra la corpulencia de sus ofrecimientos carnales, pero más allá de tal celebración revela los matices del poder y del erotismo cuando el Otro no puede desafiar al amo ni a la cultura dominante. ${ }^{9}$

En sintonía con "Pardo Adonis", "Lullaby mayor" resulta una morbosa canción de cuna donde se sobrestima al hombre para mantener la centralidad de la mujer, quien como voyeur, 'madre' y amante contempla el cuerpo dormido del hombre. La transgresiva canción de cuna implora por el eterno sueño del amado tras la entrega erótica porque así la mujer lo retendría y lograría exclusividad amorosa. Aunque la ternura materna distingue a las poetas coetáneas con Lair, la morbosa ternura de "Lullaby mayor" delata que la voz poética se enuncia desde la noción patriarcal de que la presencia masculina ofrece seguridad sicológica a la mujer:

Duerme, mi niño grande; duerme mi niño fuerte:

que el juego del amor rinde como la muerte.

[...] Me quedaré a tu lado quieta, casta e inerme,

mientras tu alma sueña, mientras tu cuerpo duerme.

[...] (Marullo del mar, cállate; sepúltate coquí!

¿Qué así dormido o muerto, quién lo aleja de mí!)

Duerme, mi niño fuerte; duerme, mi niño grande:

El sueño de la vida con la muerte se expande...

(¡Porque no amara a otra, que ni a mí misma amara!

Que la tierra por siempre sus brazos desquiciara!

$$
\text { ¡Ay, si no despertara!) (32-33) }
$$

Como en "Los sonetos de la muerte" de Mistral, la entrega de la voz poética homenajea a un cuerpo en reposo pero a diferencia, el cuerpo en reposo de Lair ofrece bienestar emocional. "Mientras tu alma sueña, mientras tu alma sueña" esta 'madre' y amante recibe el mismo sosiego que una madre cuando su "niño fuerte" duerme. La contemplación y la efímera posesión se convierten en un acto de necrofilia, pero sin el acto erótico, motivo por el cual ella se queda "quieta, casta e inerme" reconociendo el peligro de su felicidad en el verso final: “¡Ay, si no despertara!”(33). Sin duda la

9 Lair confirma el estatus de irrelevancia del sujeto afro-caribeño en el poema "Impromptu" en Arras de cristal. El poema celebra la conjunción de la raza española y la indígena sin mencionar la africana como otra raza fundacional de Puerto Rico ni de las Américas. Mercedes López Baralt afirma que, "Clara Lair se rehúsa a reconocer la herencia africana del mestizaje que tenía necesariamente ante sus ojos en la isla, quedándose en la visión ingenua de un mestizaje binario, entre europeos blancos e indígenas nativos, estrenada por Simón Bolívar al contestar al caballero de Kingston en su Carta de Jamaica de 1815”(xliv)

17. Revista Iberoamericana, Vol. LXXIX, Núms. 244-245, Julio-Diciembre 2013, 703-723 ISSN 0034-9631 (Impreso) ISSN 2154-4794 (Electrónico) muerte resulta mayor bienestar que la vida porque despertar implica la fuga del amante, su retorno al espacio público donde se relacionaría con otras mujeres, y por ende la soledad de quien acuna una turbia solución ante su angustia.

En diálogo con "Lullaby mayor", el poema "Petronio" recrea la exasperación emocional de la voz en su fatigada búsqueda de un hombre; al parecer de cualquier hombre a quien pueda aferrarse con devoción. Ahora el cuerpo masculino en reposo se transforma en el narcisista dandy cuyo hermoso retrato arrebata y mata. Sí, ciertamente: "Y, me mordió la mano" (43):

\author{
Mejor que en el rosal \\ la rosa estaba en su ojal. \\ Y era amante de todo lo precioso, de todo lo brillante. \\ Sus ojos eran sólo para el matiz subido, \\ para la flor abierta, para el metal bruñido; \\ y su amor, \\ para la pompa roja en cárdeno esplendor. \\ [...] Y porque era bello, y fuerte, y afortunado,
}

era querido por lo que otro hubiera sido odiado. (43)

El ostentoso cuerpo y la destreza de representarse y cautivar audiencias convierten a este hombre en el exquisito deleite visual asociado con Cayo Petronio Arbitro, cónsul y dictador de la moda y elegancia e íntimo amigo del emperador romano Nerón. Lair recurre a la dudosa biografía del escritor medieval de El Satiricón tales como su indulgencia, su irresistible presencia e infinitos encuentros eróticos para retratar la petulancia masculina y añadir a la historia de la voz poética en la hambrienta búsqueda del príncipe. Con el mismo arte retratista que fusiona la psiquis y los signos del cuerpo del "grupo de hombres secos apresurados" de Un amor en Nueva York (3), se recrea la pomposa imagen de un Petronio con "la rosa [...] en su ojal" y con la necesidad de que otros validen su ego y satisfagan sus urgencias. Este hombre es retratado como el típico dandi de la narrativa decimonónica que se las ingenia para usar al otro y satisfacer su inescrupulosa agenda. En The Dandy and the Señorito..., Gloria Ortiz traza el arquetipo de hombre exquisitamente acicalado, de gracia y destreza social, holgazán por naturaleza, vividor del patrimonio familiar, hombre de prestigio social que necesita compañía femenina para fortalecer y mercadear su autoestima repetidamente (3-22). Como enuncia la voz poética: "había en él un ansia amorfa de poseerlo todo [...] la mujer superfina y la hembra rumiante/la emoción exquisita, la sensación asqueante..." (43). No obstante esta psiquis de dandi motiva el empeño de una mujer necesitada que aspira a reformar las díscolas apetencias masculinas:

[...] Yo lo encontré en mi vía obcecado y perdido; enfermo de un mal raro que nadie ha padecido: [...]

Revista Iberoamericana, Vol. LXXIX, Núms. 244-245, Julio-Diciembre 2013, 703-723 ISSN 0034-9631 (Impreso) ISSN 2154-4794 (Electrónico) 
Atropellando el bien y contrito del mal.

icon impulso de rayo y choque de cristal!

"Por él quise el milagro de encender la tiniebla;

de emblanquecer el cuervo, de alquitarar la niebla...

Por él hice el esfuerzo de estrujar el gusano

que había en su alma de lodo...jY me mordió la mano! (43)

La reversión de tal psiquis - convertida en veneno- presenta el des/encuentro total de los amantes. Mientras el hombre idolatra su cuerpo y le urge admiración y servicio, la mujer entrega su vida reformando a esa "alma de lodo" porque cree que su Petronio alcanzará esplendor espiritual. Ella también evidencia carencia de amor, soledad y deseo de pertenencia; por tanto la reversión de la díscola psiquis del hombre se convierte en su luz creyendo que el "obcecado y perdido" valora la entrega de la mujer que se sacrifica y sirve a todos los hombres de su vida en búsqueda de validez social dentro de la configuración patriarcal. Mediante tal entrega la amada anticipa su anulación tras emprender un devastador proyecto y se devela como mujer obcecada mediante la urgencia sicológica de servir y sacrificarse. La mordida de la mano evidencia que este hombre emerge desde su propia adoración sin apreciar ni reciprocar la ingenua voluntad de la amada. Amar a este dandi Petronio revierte el suicidio del escritor y dictador de la moda medievalista; ahora es la mujer quien se desangra con sus acciones. Ella devela la descentralizada psiquis femenina de quien intenta transformar al sapo en príncipe a través del beso.

Como se evidencia, los hombres de Un amor en Nueva York y de Arras de cristal ignoran y humillan con orgánica desfachatez como si esta fuera su primera naturaleza. También se evidencia cuán locuazy perspicaz es la voz poética que divulga abiertamente la psiquis de los géneros según emerge de su experiencia. Los sinsabores de estos des/ encuentros le permiten a la amada vengar los atropellos sufridos lastimando la virilidad erótica, propiedad de la que alardea el hombre para confirmar su masculinidad. El poema "Después" exhibe la elocuencia del cuerpo después que el hombre eyacula y luego se acomoda para continuar su sueño mientras la mujer todavía espera su satisfacción erótica:

¡Qué ha de decirte mi mirada loca ni de mi gesto de voluptuoso giro, a ti, que tienes ya en la boca,

la risa tras el suspiro

Qué ha de traerte mi temblor de exceso

ni de mi abrazo los resortes sabios,

a ti, que tienes ya en los labio

tras el beso el bostezo! (24)
El letargo del hombre frustra a su pareja cuando él finge incapacidad para codificar el elocuente mensaje femenino. Con su "mirada loca" "voluptuoso giro" y "temblor de exceso", ella reclama que el coito no ha concluido, pero la risa, el suspiro y el bostezo del hombre afirman lo contrario. Tal elocuencia corporal implica que el deseo femenino no se considera porque el libido del hombre en su poder y derecho ya se satisfizo. El decreto patriarcal milenario que no permitía que la mujer hablara de política, religión o ciencias mucho menos permitió que la mujer pensara, disfrutara o demandara satisfacción sexual. Por ser éste un tema que arrastra complejidades para conversar con la pareja, la mujer recurre a su ingenio y del cuerpo insatisfecho eclosiona su vívida y muda protesta para comunicar que la verdad masculina no es absoluta. El lenguaje de la mujer resulta una amenaza para quien se aprehende a la autoridad que le otorga su género; pero como el acto no trasciende más allá del silencio, la mujer queda no tan sólo insatisfecha sino derrotada tras el reclamo. Si esta mujer hablara, también perdería por las implicaciones sociales e insultos que mancillarían la verdad de su deseo. Ante esta verdad fisiológica y social, el hombre gana y por eso "su risa tras el suspiro" y "tras el beso, el bostezo" (24). Desde la configuración patriarcal, la mujer existe para servir al hombre, y el coito equivaldría a otro acto más de opresión que confirma el servicio femenino cuando su deseo no se valida ni se satisface. Emmanuel Reynaud en "Holy Virility" afirma que "he [man in general] purely and simple ignores woman's pleasure and reduces his own to mere ejaculation" (137). El hombre en vez de considerar a la mujer como miembro activo, reduce el placer a pasión unilateral y así devela otra verdad de su supuesta virilidad. Aunque su agenda no es capitalista, su transacción es inmediata. Así él encarna el mismo egoísmo y distanciamiento de los hombres de Un amor en Nueva York.

La urgencia por el hombre toma otro giro en “¡Don Juan!” y "Frivolidad” cuando la voz poética siente la compleja convergencia del arte amatorio masculino y el suyo tras la repetición de experiencias atropelladoras. “¿Don Juan!” recrea la leyenda oral de arte del cortejo del burlador y la seducción de la cándida mujer. Como ella sueña con su príncipe no se percata del genuino brío y del embaucamiento del personaje universal que Tirso de Molina textualizara. En el poema un ilegítimo Romeo materializa la tradiciona burla y luego alardea como el típico don Juan. Los signos de exclamación del título revelan la súbita sorpresa de la amada, quien resulta embaucada con la "suavidad y los brillos" sin percatarse de los verdaderos bríos (25):

Habrías de llegar, tú, mi Romeo,

en suavidad y brillos.

Habrías de llegar, mi caballero,

en blancuras y bríos.

[...] Llegaste al fin.... iya muerta mi ternura!

Llegaste frío, cínico, fatal..

Revista Iberoamericana, Vol. LXXIX, Núms. 244-245, Julio-Diciembre 2013, 703-723 ISSN 0034-9631 (Impreso)
Vol. LXXIX, Núms. 244-245, Julio-Diciembre 2013, 703-723
ISSN 2154-4794 (Electrónico)
Revista Iberoamericana, Vol. LXXIX, Núms. 244-245, Julio-Diciembre 2013, 703-723 ISSN 0034-9631 (Impreso) 
Retando sombras, pisoteando tumbas:

¡Don Juan, Don Juan! (25)

Tras la repetición de la misma fórmula, urge no tolerar más las fechorías que la amada ha permitido; por ende tras la acumulación y experimentación emerge una nueva fórmula defensiva en "frivolidad", la que admite la entrega sexual del cuerpo sin involucrarse sentimentalmente. Toril Moi en Sex, Gender and the Body afirma que "Other situations as well as our particular lived experience will influence our projects, which in turn will shape our experience of the body. In this way, each woman's experience of her body is bound up with her projects in the world" (66). La incompatibilidad amatoria arruina el proyecto de la voz poética en su búsqueda del príncipe azul iniciado en Un amor en Nueva York por la "taquígrafa... que le calla un amor" (9). La devaluación y la frustrante experiencia confirman que la mujer no puede socavar más su existencia en su deseo de fusión sin la reciprocidad masculina. "Frivolidad" encarna la nueva voz que supera la desilusión amorosa y a cambio reciproca la misma frivolidad masculina. El poema también revela cuánta crueldad sicológica habita en el hombre y cómo su búsqueda desenfrenada del placer mutila el cuerpo y el espíritu de la amada. Es entonces cuando las marcas del cuerpo crean un nuevo proyecto que subvierte la frivolidad del hombre:

Y así dije al amado: marcharemos juntos unidos.

Será tu nombre el eco de todos los sonidos.

Me trazará el camino la huella de tus pasos.

Me abrirá el horizonte la curva de tus brazos

Le gritaré a la vida: ¡rompe, destroza, daña!

Yo tengo mi refugio: ¡su pecho es la montaña! (34)

Tal compenetración satisface el encantamiento de la amada quien invalida su existencia y es representada y absorbida en las ejecuciones del hombre. Él traza caminos y abre horizontes mientras ella lo sigue; a ella tampoco le importa si la vida "rompe, destroza, [o] daña" porque en su imaginario, él es su refugio. En el fragmento "Adorable", Roland Barthes expresa que "por una lógica singular, el sujeto amoroso percibe al otro como un Todo [...] y, al mismo tiempo, ese Todo le parece aportar un remanente, que él no puede expresar. [...] y este todo se lo concede bajo la forma de una palabra vacía, puesto que Todo no podría inventariarse sin disminuirse: en ¡Adorable! [...]" (27) Esta fue la primera experiencia de la voz cuando llega el Romeo de “iDon Juan!” y el nuevo Romeo de "Frivolidad". Tal adoración produce que se desafíe la vida con su grito porque idealiza al hombre como héroe protector y fiel hasta que eclosiona el desengaño:

[...] Mis ojos hechos llanto, mis labios hechos trizas..

¡Y su voz implacable pidiendo más sonrisas! ISSN 0034-9631 (Impreso) ISSN 2154-4794 (Electrónico)
Mi cuerpo en el silicio sangrando su querella...

Y su voz implacable diciendo: ¡sé más bella! (35)

El drama de los ojos, labios y cuerpo sangrante prueban la brutal insensibilidad que provoca el nuevo proyecto porque el hombre usa la violencia sicológica y demanda placer mediante el cuerpo y la belleza femenina. Así “[el] cuerpo en el silicio sangrando su querella" transforma la adoración en frivolidad para reclamar equidad erótica y convertir la entrega sexual en un pueril ejercicio de las trampas del libido. La frivolidad erótica es el medio por el cual ella satisface su deseo, no se involucra sentimentalmente y reciproca el mismo cinismo. En palabras de Lair:

Y ahora digo al amante: óyeme pasajero,

No me preguntes nunca hasta cuándo te quiero.

$[\ldots]$ ¡No me brindes los mimos de tus uñas, que ahora

sólo quiere collares esta gata de Angora!

Tú frívolo, yo frívola... soy tu igual, camarada.

¡No has de quitarme todo para dejarme nada! (35-36)

En “Letanía egoísta” la voz poética se distancia de la dependencia física y sicológica del hombre en vías de consolidar su nuevo proyecto personal después de enfrentarse al pasado que la convirtió en placer masculino. La repetida interjección dolorosa "¡Ay...!" confirma desaciertos y enmiendas, los que emergen de la reflexión de su experiencia con los hombres y de la configuración patriarcal desde donde emerge como mujer. Ahora prioriza y robustece su otra identidad e invalida al hombre para así salvarse de la opresión y desafuero masculino:

¡Ay, sólo quisiera

vivir las mismas cosas de distinta manera!

¡Volver a florecer; saberme florecida;

y balancearme al ritmo más quieto de la vida!

En el jardín salvaje del amor ser altiva

planta, que no florece sino al que la cultiva.

Desterrar de mi torre de reposo y de pan,

la pirueta a lo absurdo de Pierrot y Don Juan. [...] (39)

Con la misma pasión que la amada enunció su incondicional entrega en "Frivolidad", ahora expresa: "No dar nada de más: dar sólo lo pedido/y retirarlo al punto si no es retribuido" (39). "Letanía amorosa" equivale al momento cumbre del bildungsroman lírico cuando la voz poética contempla la trayectoria de su vida y finalmente visualiza
Revista Iberoamericana, Vol. LXXIX, Núms. 244-245, Julio-Diciembre 2013, 703-723 ISSN 0034-9631 (Impreso) ISSN 2154-4794 (Electrónico) 
que su lugar junto al hombre no es la opresión ni el servilismo ni la entrega desbocada. ${ }^{10}$ El proceso de crecimiento y aprendizaje dictaminan enaltecimiento de su ser total y por eso emite su nueva dimensión femenina: "¡Volver a revivir, fuerte, dura y fornida, y caminar atlética y autómata la vida!” (40). La repetición al principio, en el medio y al final del poema de los versos: “¡Ay, sólo quisiera/ vivir las mismas cosas de distinta manera!" equivale a la letanía, a deidad omnipotente en búsqueda de presta intervención pero con la salvedad de que ella misma se escucha y ejecuta su propia filosofía para sí Dentro de su nueva letanía egoísta no existe ningún hombre en calidad de deidad que establezca su vida. Allí su aprendizajey transformación confirmados en el poema “Arras”.

Ahora que no añoro; ahora que no sueño;

ahora que en mi senda fijo preciso el pie...

todo lo que te diera es todo lo que llevo,

es todo lo que traigo, sin antes, sin después.

[...] Es mi puro presente el que te dono;

es este instante en que soy tierra cultivada y experta...

¡Tierra rebelde de donde el otoño,

casi no puede echar la primavera! (42)

La repetición del "ahora" intensifica el aprendizaje logrado cuando revierte la configuración patriarcal que fraguó su primigenia identidad. Paradójicamente los hombres intervinieron para que se produjera tal trascendencia pero el crédito le corresponde a la voz poética, quien sintoniza con sus adentros y transfigura la opresión en libertad. Nancy Chodorow afirma que: “[...] femininity and female role activities are immediately apprehensible in the world of her daily life. Her final role identification [de la niña y adolescente] is with her mother and women" (51). Aunque la convivencia con estas mujeres podría generar soberanía sicológica, poemas como "Don Juan" "Lullaby mayor", "Pardo Adonis", "Petronio", "Después"y "Frivolidad" prueban que el entorno de la voz poética produjo lo contrario. A pesar de que no hubo modelos liberados de la opresión masculina, la experiencia encarnecida en su cuerpo y espíritu cancela la configuración patriarcal desde donde emerge como mujer nueva. Como consecuencia transformadora, urge "ahora" distanciamiento y diferenciación tanto del hombre como de la mujer tradicional.

El azar no obra para que el poema "Pasa" cierre Arras de cristal con ecuanimidad sino la clarividencia de Clara Lair, quien reconoce los pugilatos y la evolución de su voz poética desde su primer poemario y concluye con broche de oro en el segundo. "Pasa" fusiona lo vivido y divulga con precisión el proyecto de vida fraguado. Tras

${ }^{10}$ Para información de la novela de aprendizaje o bildungsroman véase The Way of the World: The Bildungsroman in European Culture de Franco Moretti.

Revista Iberoamericana, Vol. LXXIX, Núms. 244-245, Julio-Diciembre 2013, 703-723 ISSN 0034-9631 (Impreso) ISSN 2154-4794 (Electrónico) experimentar los atropellos y las disfunciones masculinas repetidamente, la amada socava su inmunología amorosa y por tanto le urge reinventar mecanismos de defensa ante estos hombres tan patéticamente cotidianos. La voz poética expresa: "yo he catado el cansancio/ de lo que el tiempo deja seco y rancio", por lo que ahora emprende su nuevo saber de mujer con la autoridad absoluta de su cuerpo y espíritu una vez se libera de la opresión (46). Así se expresa en "Pasa":

Pasa de largo y no te quedes...Sé en mí como la brisa. Fugitiva, imprecisa

nos roza apenas, sigue su rumbo, y nunca vuelve...

Yo he catado el cansancio

De lo que el tiempo deja seco y rancio...

Yo he bebido sin sed lo que el vivir ofrece..

Y, por dormir sin sueños, al día le he gritado ¡anochece!

Sigue tu rumbo...no detengas el viaje.

Nuestro encuentro es un breve mudar del equipaje.

$[\ldots]$ iNo sostengas mi mano

porque apure de pronto la gota de ilusión!

Pasa de largo y no te quedes... ¡No me mires al fondo! iMi fondo, turbio y hondo,

donde el instante es la única fragancia de mi vida

La constancia es acero, y yo soy blanda y ágil.

Rózame, como roza lo bello, en onda frágil.

Pasa de largo...no te quedes... ¡En la orilla de acá,

Fui siempre pasajera del barco que se va! (46)

Ahora después de los momentos de aprendizaje gracias al cansancio catado y a las noches de reflexión cuando gritó "!anochece!", le indica el estatus efímero a los hombres en su vida; por lo que ella ya no quedará devastada: "Pasa de largo y no te quedes... Sé en mí como la brisa" (46). De tanto catar, reconoce la amargura de la lengua que embauca y la caricia fingida que disfraza la excitación erótica con el amor. Como "pasajera del barco que se va", ella fue conquistada, desvalorizada y abandonada; por lo que se considera poco privilegiada en el amor. Dentro de su reflexión, sabe que todavía urge mayor recuperación ya que se visualiza con fondo "turbio y hondo". Ante la formulación de estos nuevos saberes, la voz poética enfatiza tres veces "pasa de largo... no te quedes..." (46). "Pasa" sintetiza cuán extenuante es crecer en el des/ amor con testimonios de certeza, liberación y logro. Su disposición para rogar, servir y adorar incondicionalmente es parte del pasado que la impele ahora al futuro dentro de su presente. ISSN 0034-9631 (Impreso) ISSN 2154-4794 (Electrónico) 
Barthes afirma en Fragmentos de un discurso amoroso que: "la catástrofe amorosa está quizás próxima de lo que se ha llamado, en el campo psicótico, una 'situación extrema', que es 'una situación vivida por el sujeto como algo que debe destruirlo irremediablemente"" (54). Arras de cristal testimonia la trascendencia de la mujer cuando la experiencia y la inmanencia del cuerpo la llevan a un estado de conciencia superior al del hombre y no a la situación extrema. La catástrofe amorosa es evidente y una posibilidad como afirma Barthes, pero la exploración de la mujer con los hombres la encamina a una evolución edificante y no a la destrucción personal. En su evolución, la voz poética que descubre cuán distante se encuentra del hombre ya que éste no entiende o ignora la ilusión femenina en sus aspiraciones más concretas que la satisfacción de libido. También descubre que el hombre no puede obrar sin oprimir. Reynaud afirma que " $[. .$.$] he [el hombre] sees woman as unrestrained flesh, a body over which the head$ has, no control" (142). Tal visión patriarcal acompaña todos los días a los hombres de Clara Lair, y perpetúa la opresión de la mujer como presa deseada y devaluada una vez la necesidad masculina queda satisfecha.

Después de la ruin experiencia, la voz poética descubre una realidad más edificante que el aferramiento al hombre para reconstruirse. Barthes afirma en que: "lo que el amor desnuda en mí es la "energía". Todo lo que hago tiene un sentido (puedo pues "vivir", sin quejarme), pero ese sentido es una finalidad inasequible: no es más que el sentido de mi fuerza" (31). Aunque la amada nunca siente tal "energía" en Arras de cristal, ahora en su nuevo proyecto muestra el mismo espíritu gladiador para reconstruir su identidad. En su momento cumbre en el bildungsroman lírico la mujer evidencia que no es "unrestrained flesh, a body over which the head has, no control" (Reynaud 142). Todo lo contrario. Con la emersión del control, también se reactiva la búsqueda de la felicidad y la intensidad de vivir cada nueva experiencia. La voz poética acepta el fracaso, sigue adelante y evidencia que no necesita la "energía" del amor ni el hombre inadecuado porque ha desarrollado independencia sicológica y visión de cómo encaminar su existencia. Una respuesta contraria sería la negación a su cuerpo y alma, y al proyecto de vida que redescubre: "[...] ¡Volver a revivir, fuerte, dura y fornida/ y caminar atlética y autómata la vida! (40)”. ¿Y el hombre, qué? Clara Lair sugiere que habría esperanza si las arras no fueran de cristal. Pero la sabiduría desarrollada se adelanta y enuncia "[...] No dar nada de más: dar sólo lo pedido;/ y retirarlo al punto sino es retribuido" (39). Para que las arras no sean de cristal la relación de pareja depende de la retribución, de la mutua asociación, respeto del cuerpo y simetría cultural. Pero la disociación de cuerpo y del alma ha violentado la dinámica ya que los hombres de Lair habitan en una dimensión diferente. Como demuestra la poeta, las arras de cristal caracterizan el frágil compromiso, la apetencia frugal y la movilidad inmediata del hombre.
"En este instante en que soy tierra cultivada y experta..."

Sin duda la galería de retratos masculinos que exhibe Clara Lair en Un amor en Nueva York y en Arras de cristal aparenta diversidad pero la psiquis operativa de los hombres los unifica en la disfunción. La psicosis y obsesión de "El Príncipe de Park Avenue", el ruego a "Pardo Adonis", los venenos de "Petronio", la impostura de Romeo, la desfachatez de " ¿Don Juan!", y la frivolidad de todos conducen al caos. No obstante ni la degradación, ni el desengaño amoroso, ni el cansancio catado han sido obstruccionistas ya que la voz poética evidencia que posee mayores bríos; y con tales bríos desmantela el patetismo de su interacción con los hombres. Esta corpulencia espiritual le permitió desentrañar los desafíos ocultos y latentes de la potestad masculinidad que representa una falsa verdad pública del hombre para entonces socavar todo título de magnanimidad de los príncipes o Petronios. Aunque la disfunción no es exclusividad del hombre parece no haber otra voluntad ya que los afilados poemas enuncian al libido impetuoso o la psicosis del dinero del hombre como energías que remueven y violentan todo. También en la galería de retratos, Lair exhibe al hombre incapaz de expresar emociones auténticas, hombres que practican violencia psicológica, hombres cuya impecable presencia y vanidad obliteran fealdades, hombres asustados de su vulnerabilidad, hombres que reprimen sentimientos nobles pero fanfarronean pesares, hombres indiferentes al eros femenino, y hombres temerosos de una relación substancial con su pareja. La configuración de esta conducta licenciosa y destructiva no permite nunca la emersión de las cualidades positivas del hombre. La fijación de la voz poética se concentra en su pena, en la historia del fracaso masculino y femenino para documentar una estructura social inoperante. "En este instante en que soy tierra cultivada y experta", la im/posibilidad de compañía se mantiene vigente con los nuevos baluartes de existencia para implementar su formulación como mujer nueva y una poética amatoria más trascendental, donde se experimente un nuevo saber entre el hombre y la mujer.
Revista Iberoamericana, Vol. LXXIX, Núms. 244-245, Julio-Diciembre 2013, 703-723 ISSN 0034-9631 (Impreso)
Revista Iberoamericana, Vol. LXXIX, Núms. 244-245, Julio-Diciembre 2013, 703-723 ISSN 0034-9631 (Impreso) 


\section{BiBLIOGRAFÍA}

Barthes, Roland. Fragmentos de un discurso amoroso. México: Siglo Veintiuno Editores, 1982.

Benítez Rojo, Antonio. La isla que se repite: el Caribe y la perspectiva posmoderna. Hanover: Ediciones del Norte, 1989

Burkert, Walter. Greek Religion. John Raffan, trad. Cambridge: Harvard UP, 1985.

Belén, Ivonne, dir. Una pasión llamada Clara Lair. SEDCP, Inc. 1996.

"Razón de una pasión: ¿por qué un documento sobre Clara Lair". Lenguaje y poesía. Carmen Cazurro de García de la Quintana, ed. Puerto Rico. 199-205.

Cañas, Dionisio. El poeta y la ciudad: Nueva York y los escritores hispanos. Madrid: Cátedra, 1994.

Chodorow, Nancy. "Family Structure and Feminine Personality." Woman, Culture and Society. Michelle Z. Rosaldo y Louise Lamphere, eds. Stanford: Stanford UP, 1974. 42-66.

Edley Nigel y Margaret Wetherell. Men in Perspective: Practice, Power and Identity. London, New York: Prentice Hall/Harvester Wheatsheaf, 1995.

Ferré, Rosario. “Entre Clara y Julia”. Revista Iberoamericana 52/137 (1986): 999-1006. Fábulas de la garza desangrada. México: Editorial Joaquín Mortiz, 1982.

Géigel Polanco, Vicente. Clara Lair: Obra Poética. San Juan, Puerto Rico: Instituto de Cultura Puertorriqueña, 1979.

Gould, Robert E. "Men, Money and Masculinity." Money and Mind. Sheila Klebanow y Eugene L. Lowenkopf, eds. New York: Plenum Press, 1991. 61-67.

Hallowell, Edward M. y William J. Grace, Jr. "Money Styles". Money and Mind. Sheila Klebanow y Eugene L. Lowenkopf, eds. New York: Plenum Press, 1991. 15-26.

Levant, Ronald F. "Toward the Reconstruction of Masculinity". Journal of Family Psychology 5/3-4 (1992): 379-402.

López Baralt, Mercedes. De la herida a la gloria: La poesía completa de Clara Lair Puerto Rico: Terranova Editores, 2003.

Marcel, Detienne. The Gardens of Adonis: Spices in Greek Mythology. Janet Lloyd, trad. New Jersey, Humanities Press, 1977.

Mistral, Gabriela. Desolación. Madrid: Colección Austral, 1972.

Moi, Toril. Sex, Gender and the Body. New York: Oxford UP, 2005.

Moretti, Franco. The Way of the World: The Bildungsroman in European Culture. London: Verso, 1987.

Ortiz, Gloria. The Dandy and the Señorito: Eros and Social Class in the NineteenthCentury Novel. London: Garland Publishing Inc.,1991.

Pieropan, María D. "Alfonsina Storni y Clara Lair: De la mujer posmodernista a la mujer 'moderna"”. Hispania 76/4 (1993): 672-682.
Reynaud, Emmanuel. "Holy Virility: the Social Construction of Masculinity." Feminism \& Masculinities. Peter F. Murphy, ed. Oxford, New York: Oxford UP, 2004. 136- 148.

Rosario Vélez, Jorge L. "Registros de la patria y la nostalgia en Gertrudis Gómez de Avellaneda y Lola Rodríguez de Tió. Revista de Estudios Hispánicos 31/1 (2004): 83-104.
Revista Iberoamericana, Vol, LXXIX, Núms. 244-245, Julio-Diciembre 2013, 703-723 ISSN 0034-9631 (Impreso)
Revista Iberoamericana, Vol. LXXIX, Núms. 244-245, Julio-Diciembre 2013, 703-723 ISSN 2154-4794 (Electrónico) 
